\title{
Preliminary study on leadership proximity
}

\author{
Valentina Mihaela GHINEA \\ The Bucharest University of Economic Studies, Bucharest, Romania \\ valentina_ghinea@yahoo.com \\ Ramona CANTARAGIU \\ The Bucharest University of Economic Studies, Bucharest, Romania
}

\begin{abstract}
In general, it is agreed that effective leadership requires a certain degree of proximity, either physical or mental, which enables leaders to maintain control over their followers and communicate their vision. Although we agree with the leadership proximity principles which states that leaders are able to efficiently serve only those people with whom they interact frequently, in this article we focus instead on the disadvantages of being too close and the way in which close proximity can actually hurt the effectiveness of leadership. The main effects that we discuss regard the way in which proximity and familiarity allow followers to see the weaknesses and faults of the leader much more easily and thus diminish the leader's heroic aura, and the emotional bias that results from a leader being too familiar with his followers which will impede the process of rational decision making. As a result, we argue that there exists a functional proximity which allows the leader the necessary space in which to perform effective identity work and to hide the backstage aspects of leadership, while also allowing him an emotional buffer zone which will enable him to maintain the ability to see clearly and make rational decisions.
\end{abstract}

Keywords: leadership, proximity, emotional bias, functional proximity, emotional buffer, Gulliver effect.

\section{Introduction}

Leadership is encountered in every society as it is necessary for the well-functioning of organizations and groups, independent of the will and the level of awareness of the individuals (Globe, 1999). Throughout the time, and especially during the last few decades, our understanding of leadership and management has undergone several transformations. If until the 1940s most leadership theories were focused on the personal traits of leaders (according to these theories, leadership was a function of the abilities and personal characteristics of leaders), between the 1940s and the 1960s, personal styles of leadership became more prominent. Going further, during the 1960s and 1980s, scholars began to conduct researches on the mixed conditioning between the traits of the leaders and their followers, focusing on particular situations and circumstances, and, in the 1980s and 1990s the theory of transformational leadership appeared.

These theoretical advancements have been inspired by the development of interdisciplinary studies (e.g., socio-economy), new leadership dimensions, such as that of emotional intelligence introduced by Goleman (2004), and by the increased complexity of modern organizations in which it is no longer feasible to talk about leadership only in terms of management positions and formal leaders. The emphasis currently placed on collaboration and not on competition, and the frequent changes in the economic and social contexts have created the need for a new approach to leadership, one that departs from the individualistic model (based on the identification of the set of attributes and characteristics 
that defined the ideal leader) and that focuses on the perspective of the leader whose actions have to be taken into consideration in the context of his/her interdependence with the group being led. Thus, today leadership has to be understood as a complex social dynamic phenomenon that is shared, relations, global and strategic (Avolio et al., 2009). However, current management and leadership studies have neglected the analysis of these integrated and complementary processes/activities (Bolden, 2007).

PICBE $\mid 961$

Irrespective of whether we talk about leaders of small groups or leaders of tribes, states and nations, it readily becomes apparent that there are three determining factors that influence one another: the leader (described by a series of traits, knowledge and abilities), the group (with its own characteristics) and the environment. As such, leadership can be conceived as the process of influencing the members of a social group and the ability of determining them to cooperate voluntarily in order to attain a common goal (Kim et al., 2011).

In regards to the modern study of leadership we can cite Terman and his investigation into the psychology and development of leadership at the start of the $20^{\text {th }}$ century, Freud's analysis of group psychology and Weber's theory of charismatic leadership (Bass and Bass, 2008). The empirical researches inspired by these theories have proven that leadership is important for the success of all organizations both through its direct influence and through an indirect influence related to improving morale by offering rewards, correlating rewards with performance and ensuring that everyone is treated justly (Avolio et al., 2009). For example, the experiments conducted by Bass and Bass (2008) have shown that authentic leadership can improve results by up to $60 \%$, which makes it critical for the wellbeing of modern organizations.

Without the intention to conceive another leadership theory, the present paper proposes a new approach that would seeks to model the unexplainable glory that leaders apparently suddenly enjoy and their unexpected falling into de-mystification if not even disgrace. We argue that there is what we call a functional proximity which gives the leader the possibility to create a strong enough connection with his potential followers, without uncovering the backstage aspects of leadership (e.g. petty human flaws) that generally causes obsolescence.

\section{Emotional Intelligence and leadership}

Goleman's empirical research has proven that, in spite of the existence of several types of leadership, all leaders share a common trait: that of being emotionally intelligent. His studies have also emphasized the fact that the importance of emotional intelligence increases as we go up the hierarchical ladder, due to the fact that for higher management positions technical knowledge is negligible as a differentiating factor between effective and ineffective leaders (Goleman, 2004; Gardner and Stough, 2002). In other words, the qualities usually associated with the traditional leader (e.g., intelligence, tenacity, determinization and vision) are necessary, but not sufficient for being a successful leader: "IQ and technical competences are important, but emotional intelligence is the indispensable condition of leadership" (Goleman, 2004, p. 1).

Thus, in contrast to traditional thinking that emotions are opposed to rationality and that they reduce the efficiency of leadership (Ashforth and Humphrey, 1995), the immediate conclusion inspired by Goleman's study is that true leaders are, in fact, effective managers of emotions, which means that they know themselves, they are able to self- 
regulate their emotions, to motivate others, to and show empathy and other social competences. According to Whetten and Cameron (2011), these fundamental human abilities continue to constitute the essence of efficient human interaction in spite of all the latest technological advancements.

The latest medical discoveries have attested a genetic component of emotional intelligence (which can be improved through education) (Tiberius, 2002) and have also identified the parts of the brain which are responsible for emotional intelligence - the limbic system of the nervous system (the one responsible for feelings, impulses and stimuli) (do Amaral and de Oliveira, n.d.). Moreover, researchers have also uncovered that emotional intelligence develops with age, finding a correspondent in what is commonly known as maturity (Goleman, 2004; Maddocks, 2011). In accordance to these biological and biographical theories, certain scholars have argued in favor of introducing the study of the lives of leaders, including family history, as predictive variables for their type of leadership (Howell and Shamir, 2005).

Initially regarded from a neurobiological perspective, the symbiosis between leaders and followers has been shown to be founded on a chemical connection realized between the central nervous systems of both parties, which explains why moods are contagious and how groups can reach a state of emotional cohesion. This type of mood contagion (Goleman and Boyatzis, 2008) can help followers become more motivated in working towards common goals or can hurt group efficiency by creating a hostile or demoralized working atmosphere, and it is the responsibility of the leader to manage the group's emotions in order to stir away from negative emotional environments.

Further neuro-social and neuro-behavioral studies (the analysis of what happens inside the human brain during social interaction) have shown that the decision-making process is influenced by the hyperactivity of certain nervous cells: mirror neurons and fusiform neurons. The first category of neurons is responsible for the reproduction/copying of the emotions transmitted by other people (Barsade, 2002; Gazzola et al., 2006; Heyes, 2009; Keysers and Gazzola, 2010), which creates an immediate feeling of shared experience (Keysers and Gazzola, 2007; Tse and Dasborough, 2008; Schippers et al., 2010). The second category of neurons facilitates the transmittal of thoughts, feeling and judgements, being responsible for intuition or the social guidance system (Allman et al., 2001).

In general, scientists from the socio-economic field who neglect these medical findings, explain the existence of this talent as the ability to recognize pattern and attribute it to the vast life experience of the person, failing to take into consideration the genetic factor which determines the appearance of fusiform cells responsible in motivating/determining an individual to act, to rememorate past experiences, to admit mistakes, important processes for the appearance of an adaptive response, for self-control and for gaining a social perspective (Allman et al., 2002).

In conclusion, independent of the will and the level of awareness of individuals, due to the personal nervous structure and the dynamic of mirror neurons, both positive and negative moods are contagious and spread among team members, affecting the performance of the group (see also the empirical research performed by Bono and Ilies (2006) on emotional attachment of followers towards the leader). 


\section{Relational distance in leadership}

Although distance has not been featured prominently in previous research on leadership, scholars have started to pay closer attention to this feature and to argue that it may, in fact, be able to explain many of the outcomes of different types of leadership (Antonakid and Atwater, 2002; Hambley et al., 2007). Previous research has offered different conceptualization of leadership distance, focusing on social, physical (geographical), structural, psychological (emotional), and functional aspects (for an overview see Erskine, 2012). Synthesizing the existing ideas, the distance perceived as being necessary for the well-functioning of the leader-follower relationship is found under the name of relational distance, this concept being considered as composed of three elements: structural distance, status distance, and psychological distance (Erskine, 2009). In Erskine's view, structural distance (referring to geography, communication channels, frequency of interaction), does not have the same significant effect on productivity or performance as psychological distance.

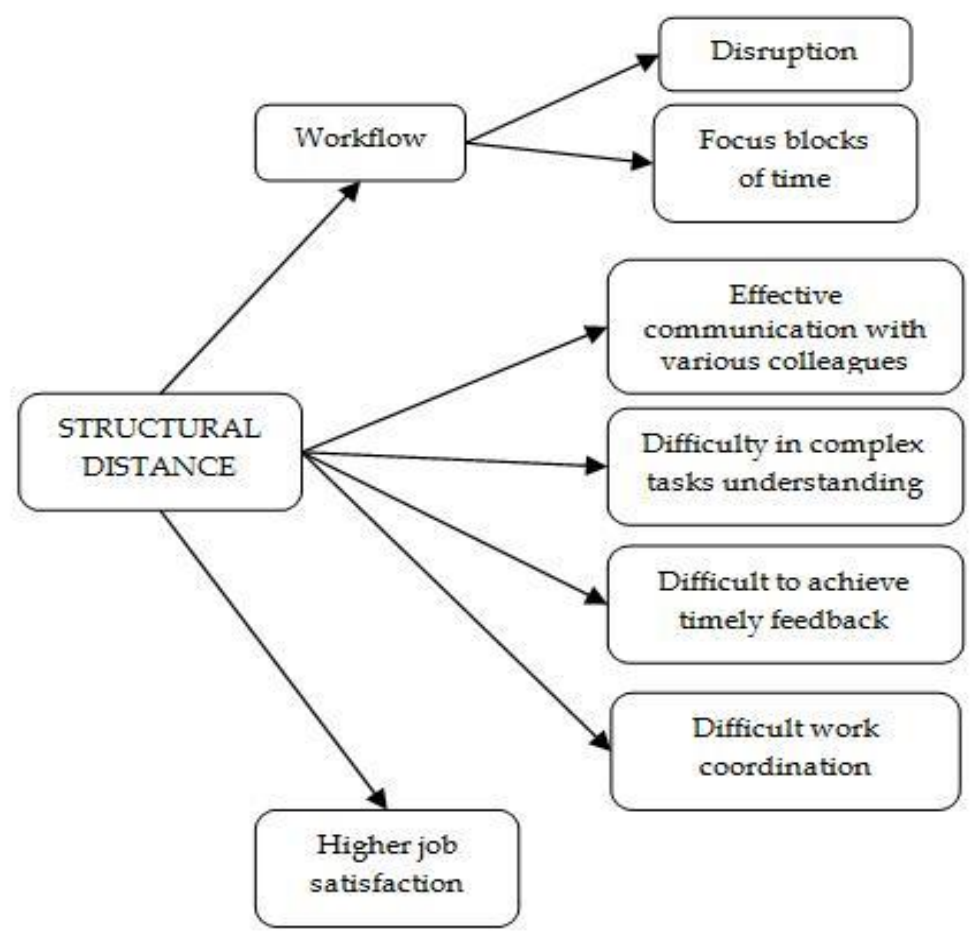

Figure1.The dynamics of structural distance influence

Source: authors' interpretation based on (Erskine, 2009).

Even we partially agreeing with the fact that structural distance might not decrease production or performance as noticed by Erskine (2009), we draw attention to the fact that it is rather about a potential lack of negative impact, and not an empirically tested conclusion. Moreover, we argue that the impact of structural distance might be counterbalanced by the dynamics of the other dimensions such as psychological distance, which is why it is necessary to view these dimensions as intercorrelated. We consider here the structural distance overlapping the regular communication process that is more or less facilitated by the length of physical distance between the so-called leader and his followers. 
In fact, it is an exaggerative appellation in this case, the causalities displayed being more convenient/suitable when an assigned managerial position is in question.

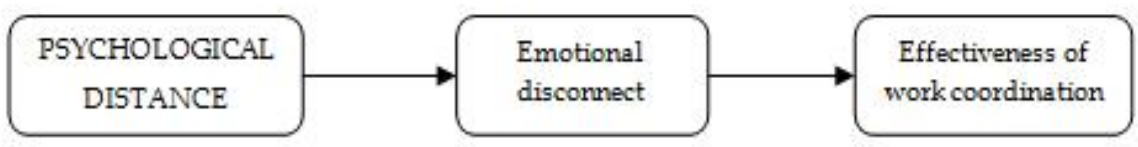

PICBE | 964

\section{Figure2.The dynamics of psychological distance influence}

Source: authors' interpretation based on (Erskine, 2009).

As far as the status distance is concerned, Erskine (2012) enlists here demographic (age, race, gender, education, experience), and social distances (power, status, rank, authority, social standing, cultural norms), as well.

No matter how rich the research in the field is, we still find the need for a functional causality explanation, especially given the very sensitive dynamics of the leadership, from flourishing to glorification and/or decline. Moreover, we argue that most of the studies investigate the transactional leaders' condition (alias managers') within the organization, and not leadership as a complex combination of transactional and transformational skills able to inspire and conduct changes, a gap in the literature that we intend to fill by focusing on the way in which leadership proximity affects the effectiveness with which leaders are able to use different mechanisms in order to move the organization towards the achievement of its strategic goals.

\section{Gulliver effect triggered by leadership proximity}

In theorizing the existence of an ideal distance between leaders and followers, one that is dictated by to the traits of the social actors involved and of the context, we make use of an analogy with the experience of Jonathan's Swift famous character, Gulliver and his adventures in Lilliput (the land of the dwarves) and Brobdingnag (the land of the giants). While Erskine (2009) looks into structural and psychological distance separately (figure 1 and figure 2), we claim that the two are interrelated and that when their effects are not balanced, leadership has to suffer the consequences (for an overview of the various negative consequences of non-functional leadership proximity see figure 5).

Effective leadership could require, in some situations, a higher or smaller structural and psychological distance between leader and followers. We do not intend to formulate a general rule as human diversity is large and the number of particular circumstances in which people find themselves is even larger. However, we do intend to emphasize that there are disadvantages when leaders are not only too far, but also too close to their followers, and that a proper balance between closeness and distance has to be sought in order to be an effective leader. Thus, leaders have to learn how to position themselves in regards to the distance from their followers in order to be as effectively as possible and we call this functional leadership proximity.

So, what happens when the distance between the leader and the followers is too short? Useful insights can be gained from Gulliver's experiences in Lilliput, the land of small people, where he was seen as a giant. First of all, Lilliputians could see him from up close and concluded that he was ugly and gross: they could see the hairs on his face, the huge pores that opened up his skin and the drops of sweat. Translated for the case of leaders that are too close to their followers, this means that closeness allows others to see their 
weaknesses and their faults much more easily and thus the leader's heroic aura is diminished. Weinberg, the author of Cluetrain Manifesto demonstrated this effect of close proximity by using photographs of celebrities without their make-up on: "[Hollywood celebrities] cease to be famous when we see them as they are" (Wortham, 2008).

Thus, drawing on the dramaturgical theory proposed by Goffman (1964, p. 4), we argue that leaders need to make a clear separation between the backstage (the space in which they prepare for their performances much like actors) and the front stage (the space where they give their performance), and that they need to regulate the access to the back regions because here is where they are "without their make-up on" and exposed to the critical glance of their followers. When the distance between leaders and followers is too short, leaders may have find it difficult to separate the two regions and followers will be able to see the instances in which they look insecure, they display their personal preferences for particular members of the group and, in general, behave with less decorum (Cicourel, 1958). Previous researches have shown that when leaders are too close, their followers tend to focus on their behaviors, whereas when they are distant, the followers make assumptions regarding their traits (Popper, 2013). Thus, it is easier for followers to nitpick and observe incongruences when leaders stand too close and to use these when formulating their opinions of them.

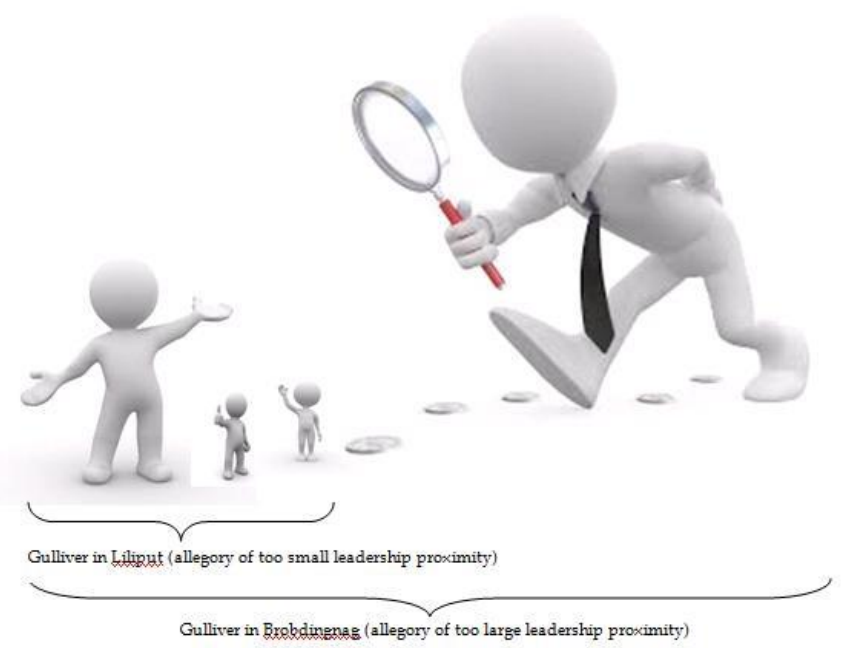

Figure3. The Gulliver effect triggered by the leadership proximity

Source: Authors' own considerations.

Moreover, when the distance between leaders and followers is not large enough, then it is impossible for followers to transform the leader into an inspiring figure, one that is larger than life and which sometimes gains mythological dimensions (e.g., Steve Jobs). Individuals have an inherent need to construct stories and symbols of their leaders and it is easier for them to achieve this if leaders are a bit distant (Popper, 2012). In the absence of such stories, it is difficult for followers to use the image of the leader for the construction of their self-worth (Popper, 2013) and leaders are left without one of the most powerful devices that they can use in order to inspire and motivate: symbolism, fantasy and storytelling (Bass, 1985), and has to rely more heavily on rewards (Shamir et al., 1993).

Being too close also has a significant impact on the leader's ability to make the right decisions. For example, the separation between front and backstage is also important because it allows leaders to obtain a degree of emotional disconnection necessary for 
making rational decisions, an ability which is limited when the leader is being too familiar with his followers. Emotional biases arising from psychological closeness may impede rational judgment and cause leaders to stall making tough decisions, thus resulting in ineffective leadership. Moreover, when leaders stand too close, they have trouble seeing the bigger picture and formulating a clear vision, due to the fact that much of their attention is dedicated to daily interactions with his followers. This can lead to a type of micromanagement that consumes the resources of the followers, much so as Gulliver consumed all the food supplies of the Lilliputians in order to satiate himself, leaving little room for the actual work that needs to be done.

How about the situation in which the leader is too far away from his or her followers? As it happened when Gulliver arrived on the island of giants and was transformed into a toy for a little peasant girl, put into a box and then paraded through town, when leaders are too distant, it is fairly easy for their followers to lose sight of their actual traits and qualities and to transform them into abstract images that can be easily manipulated. In this case, leaders have less direct control on the way in which their followers translate their vision into action and this can result in misinterpretations and unwanted distortions of the leaders' messages. Being too far, or placed in a box as was Gulliver's case, also leaves leaders with less access to the daily experiences of their followers which limits the leaders' ability to understand what their needs and desires are and how to provide the necessary motivation and guidance.

When it comes to psychological distance, it is much more difficult to maintain an emotional connection when leaders are far removed from their followers because, as previously discussed emotions are best transmitted when humans interact in close proximity in order to allow the spindle-shaped brain cells to become activated. When the leader is psychologically distant, this translates in less emotional work and this can be a serious threat to his or her authenticity, because his followers might perceive him as not displaying real emotions, but rather to be "surface acting, which involves simulating emotions appropriate for the situation that are not actually felt" (Gardner et al., 2009). Moreover, being psychologically distant means that followers will have the tendency to make an attribution error and to base their explanations of certain events on the leader's traits and abilities rather than on the circumstances (because the leaders is too far, followers have less information regarding his or her activities and followers allocate less explanatory power to things that they do not understand) (Popper, 2013). This means that distant leaders are likelier to be blamed for negative outcomes even if these outcomes are not the result of ineffective leadership.

As a result, we argue that there exists a proper proximity which allows the leader the necessary space in which to perform effective identity work and to hide the backstage aspects of leadership, while also allowing him an emotional buffer zone which will enable him to maintain the ability to see clearly and make rational decisions. 

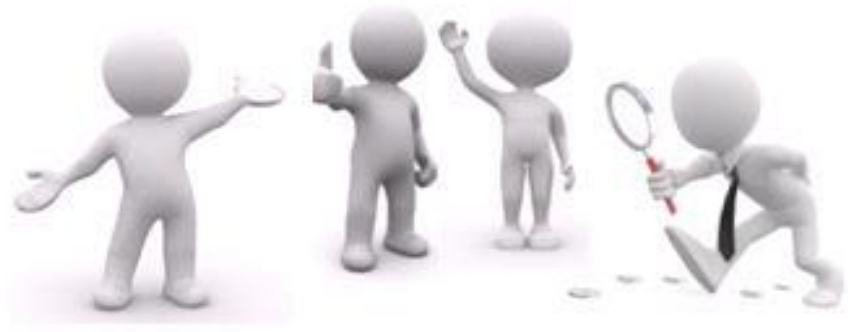

PICBE | 967

Figure 4. Leadership functional proximity

Source: Authors' own considerations.

In case of this proper proximity, the leader captures without too much effort the attention, admiration and adhesion of followers (figure 4). We therefore call this optimum distance leadership functional proximity, and we aim to measure it by means of interposed individuals that maintain vivid the magic leader-follower relationship.

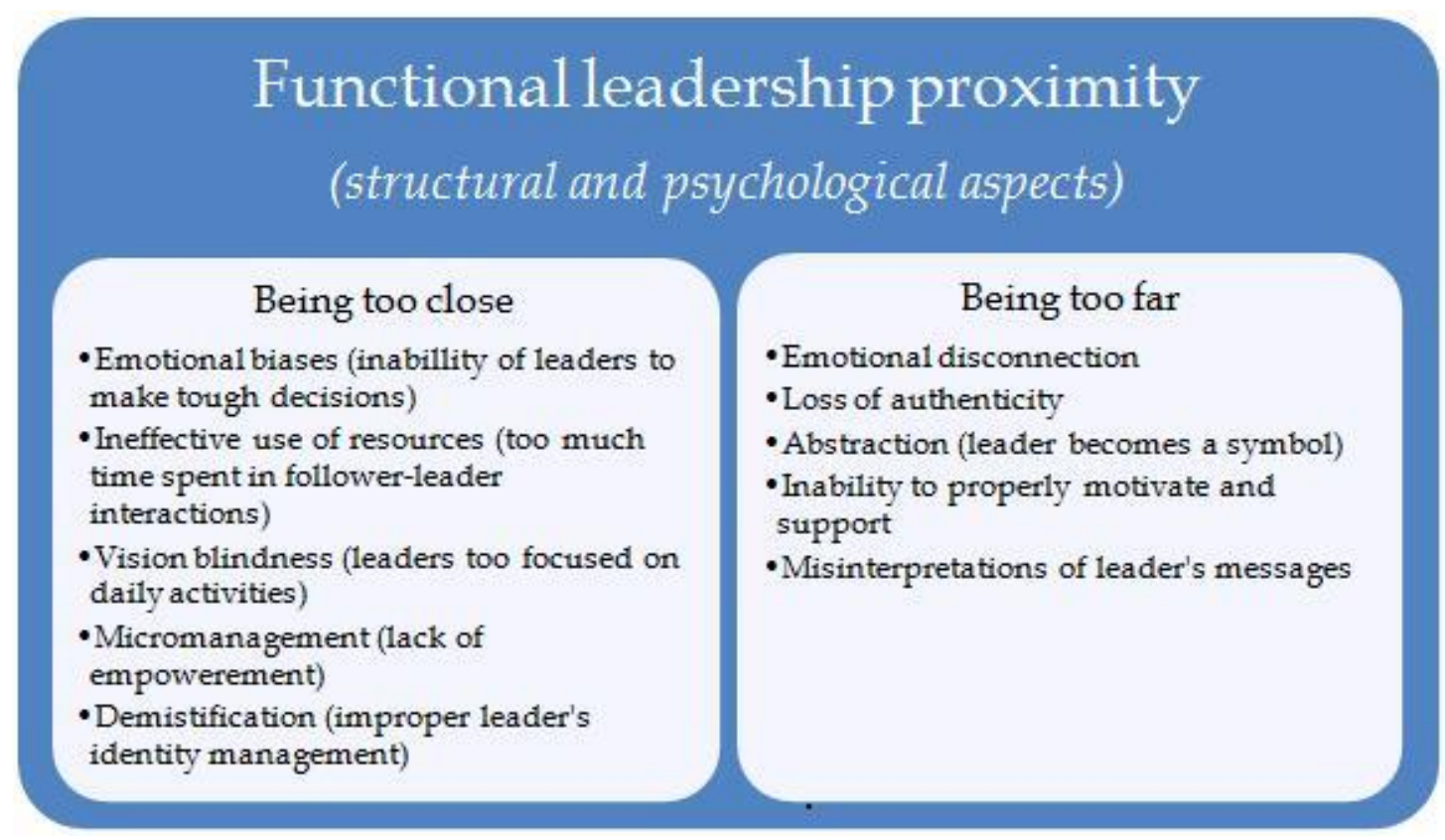

Figure 5. Effects of improper distance between leaders and followers

Source: Authors' own considerations.

\section{Conclusions}

All theories of leadership intend to a) explain how leaders appear; b) define the nature of leadership exercised by different leaders and identify the ways in which this manifests itself (both being influenced by the characteristics of the leaders); and c) measure the consequences of different types of leadership. In this paper, we have argued that measuring the distance between leaders and followers is a fruitful investigative avenue which might shed light on the dynamics between the personal characteristics of leaders, those of their followers, and the context of their interaction, enabling us to draw conclusions on how leaders come into being and how they manage to effectively motivate their followers. Using Gulliver's travels as a metaphor, we have shown the ways in which varying the distance between leaders and followers might have an impact on the ability of leaders to perform according to their role. 
This work is just a theoretical exploration of the concept of functional leader proximity and in future research we intend to create a working model which will take into consideration the interrelations between the different types of distances (structural, psychological and social) and use them in order to test the effects of improper distancing that have been presented here.

\section{References}

Allman, J.M, Hakeem, A. and Watson, K. (2002), "Two phylogenetic specializations in the human brain", The Neuroscientist, 8(4), 335-346.

Allman, J.M., Hakeem, A., Erwin, J.M., Nimchinsky, E. and Hof, P. (2001), "The anterior cingulate cortex: The evolution of an interface between emotion and cognition", Annals of the New York Academy of Science, 935, 107-117.

Antonakis J. and Atwater, L. (2002), "Leader distance: A review and a proposed theory", Leadership Quarterly, 13(6), 673-687.

Ashforth, B.E. and Humphrey, R.H. (1995), "Emotions in the workplace: a reappraisal", Human Relations, 48, 97-125.

Avolio, B, Walumbwa, F. and Weber, T.J. (2009), "Leadership: current theories, research, and future directions", Annual Review of Psychology, 60, 421-449

Barsade, S.G. (2002), "The ripple effect: emotional contagion and its influence on group behaviour", Administrative Science Quarterly, 47(4), 644-675.

Bass, B.M. (1985), Leadership and performance beyond expectations, Free Press, New York.

Bass, B.M. and Bass, R. (2008), The Bass handbook of leadership. Theory, research \& managerial applications, Free Press, New York.

Bolden, R. (2007), "Trends and perspectives in management and leadership development", Business Leadership Review, 4(2), 1-13.

Bono, J.E. and Ilies, R. (2006), "Charisma, positive emotions and mood contagion", Leadership Quarterly, 17, 317-334.

Cicourel, A.V. (1958), "The front and back of organizational leadership: A case study", The Pacific Sociological Review, 1(2), 54-58.

Do Amaral, J.R. and de Oliveira, J.M. (n.d.), "Limbic system: The center of emotions", available at: www.healing-arts.org/n-r-limbic.htm (accessed May 2, 2017).

Erskine, L. and Johnson, S.D. (2012), "Effective learning approaches for sustainability: A student perspective", Journal of Education for Business, 87(4), 198-205.

Erskine, L. (2009), "A question of leadership: What does effective leadership look like in a virtual work environment, and can Web-based leadership operate the same way that face-to-face leadership does?". Leadership in Action, 28(6), 12-13.

Erskine, L. (2012), "Defining relational distance for today's leaders", International Journal of Leadership Studies, 7(1), 96-113.

Gardner, L. and Stough, C. (2002), "Examining the relationship between leadership and emotional intelligence in senior level managers", Leadership \& Organizational Development Journal, 23(2), 68-78.

Gardner, W.L., Fischer, D. and Hunt, J.G. (2009), "Emotional labor and leadership: A threat to authenticity?", The Leadership Quarterly, 20, 466-482.

Gazzola, V., Aziz-Zadeh, L. and Keysers, C. (2006), "Empathy and the somatotopic auditory mirror system in humans", Current Biology, 16, 1824-1829. 
Goffman, E. (1959), The presentation of the self in everyday life, Doubleday Anchor. New York.

Goleman, D. (2004), "What makes a leader?", Harvard Business Review, available at: hbr.org/2004/01/what-makes-a-leader (accessed May 2, 2017).

Goleman, D. and Boyatzis, R. (2008), "Social intelligence and the biology of leadership", Harvard Business Review, available at: hbr.org/2008/09/social-intelligence-and-thebiology-of-leadership (accessed May 2, 2017).

Hambley, L.A., O'Neil, T.A. and Kline, T.J. (2007), "Virtual team leadership: Perspectives from the field", International Journal of e-Collaboration, 3(1, pp. 40-64.

Heyes, C. (2009), "Where do mirror neurons come from?", Neuroscience and Biobehavioral Reviews, 34(4), 575-583.

Howell, J.M., and Shamir, B. (2005), "The role of followers in the charismatic leadership process: relationships and their consequences", Academic Management Review, 30(1), 96-112.

Keysers, C. and Gazzola, V. (2007), "Integrating simulation and theory of mind: from self to social cognition", Trends in Cognitive Science, 11(5), 194-196.

Kim, J.H., Kim, C.S. and Kim, J.M. (2011), "Analysis of the effect of leadership and organizational culture on the organizational effectiveness of radiological technologist's working environments", Radiography, 17, 201-206.

Popper, M. (2012), Fact and fantasy about leadership, Edward Elgar, London.

Popper, M. (2013), "Leaders perceived as distant and close. Some implications for psychological theory on leadership", The Leadership Quarterly, 24, 1-8.

Schippers, M.B., Roebroeck, A., Renken, R., Nanetti, L. and Keysers, C. (2010), "Mapping the information flow from one brain to another during gestural communication", Proceedings of the National Academy of Sciences of the United States of America, 107(20), 9388-9393.

Shamir, B., House, R. and Arthur, M. (1993), "The motivational effects of charismatic leadership: A self-concept based theory". Organizational Science, 4, 577-593.

Tiberius, J. (2002), "Genetics and intelligence", available at: http://www.molwick.com/en/intelligence/050-genetics-intelligence.html (accessed May 2, 2017).

Whetten, D.A. and Cameron, K.S. (2011), Developing management skills ( $8^{\text {th }}$ ed,), Prentice Hall.

Wortham, J. (2008), "ROLFCON: Welcome to the fame revolution", Wired, available at: www.wired.com/2008/04/welcome-to-the-9 (accessed May 2, 2017). 